\title{
Anomalous right-sided pulmonary venous connection to the superior vena cava
}

\section{Connessione anomala di vena polmonare destra alla cava superiore}

\author{
Kiumars Abbasi, Ali Abbasi, Mokhtar Tazik, Abbas Salehiomran, \\ Ali Kazemisaeed, Hakimeh Sadeghian
}

\begin{abstract}
Anomalous right-sided pulmonary venous connection to the superior vena cava. K. Abbasi, A. Abbasi, M. Tazik, A. Salehiomran, A. Kazemisaeed, H. Sadeghian.

Over the years, different techniques have been introduced for the repair of sinus venosus atrial septal defect (ASD) with anomalous right-sided pulmonary venous connection to the superior vena cava. We report the case of a 9year-old girl, who presented with dyspnea and peripheral cyanosis. Preoperative echocardiography and angiography findings suggested a partial anomalous pulmonary venous
\end{abstract}

connection. On cardiopulmonary bypass, the ASD was dilated, and the anomalous pulmonary vein was anastomosed to the right atrium and redirected to the left atrium using an intraatrial baffle and a tube graft. The intraoperative and postoperative periods were uneventful, and the patient is currently in good health at 4.5 years' follow-up.

Keywords: partial anomalous pulmonary venous connection, atrial septal defect, superior vena cava.

Monaldi Arch Chest Dis 2009; 72: 37-39.

Departments of Cardiac Surgery and Cardiology, Tehran Heart Center, Tehran University of Medical Sciences, Tehran, Iran.

Corresponding author: Ali Abbasi MD; Tel. \& Fax: +98 21 88029256; E-mail: aliiabbasi@yahoo.com; Mailing address: Tehran Heart Center, North Kargar Street, Tehran, Iran, Postal code: 1411713138

Partial anomalous pulmonary venous connection (PAPVC) is a condition in which some, but not all, pulmonary veins usually connect to the right atrium or its tributaries. PAPVC may occur as an isolated anomaly or may be combined with atrial septal defect (ASD). It is present in approximately $90 \%$ of patients with sinus venosus type ASD [1, 2]. There have been several reports on operative techniques for PAPVC and follow-up findings. Repair of PAPVC to the high portion of the superior vena cava (SVC) may be complicated by atrial arrhythmia and obstruction of the pulmonary veins or the SVC. We describe a case of a right-sided PAPVC with small sinus venosus type ASD occurring in a 9-year-old girl. We adopted and modified the use of a tube graft and internal patch technique to redirect the anomalous pulmonary venous return through the sinus venosus defect by baffling the structures with a pericardial autologous pericardial flap and ASD dilatation for the pulmonary venous drainage channel.

\section{Case Report}

A 9-year-old girl was referred to our heart center for an evaluation of exertional dyspnea and peripheral cyanosis. On physical examination, a tachycardia (106 to 130 beats per min) of sinus rhythm and a grade IV continuous murmur were detected. The laboratory data showed a hemoglobin level of
$11.9 \mathrm{mg} / \mathrm{dl}$, creatine kinase $(\mathrm{CK})$ of $250 \mathrm{U} / \mathrm{L}$, and lactate dehydrogenase (LDH) of 700 IU/L.A sinus tachycardia and right axis deviation with right bundle branch block (RBBB) were detected on electrocardiography. Transthoracic echocardiography (TTE) showed right ventricular (RV) enlargement with an RV/LV ratio of 38/28. A sinus venosus ASD with right-sided PAPVC and a mild tricuspid regurgitation (TR) with PAP of $29 \mathrm{~mm} \mathrm{Hg}$ were revealed. The global LV ejection fraction (LVEF) was $55 \%$ on TTE. Cardiac catheterization and angiographic findings were consistent with those found on echocardiography (Figure 1).

At surgery, cardiopulmonary bypass (CPB) was established in a standard fashion using bicaval high SVC cannulation. After the cross-clamping of the ascending aorta, cardiac arrest was achieved using antegrade cold blood cardioplegia. The ascending aorta and SVC were dissected out to the right and left innominate veins, exposing the anomalous right pulmonary vein. The anomalous pulmonary vein was disconnected from the SVC and was extended using a No.10 tube graft (Gore-TX cardiovascular patch, GORE-TX ${ }^{\circledR}$, USA). The proximal extended pulmonary vein was anastomosed directly to the right atriotomy with due attention to avoid injury of the sinus node. A pulmonary venous drainage channel was formed via an intraatrial baffling from the open window in the right atrium to the enlarged sinus venosus ASD using an autologous pericardial 

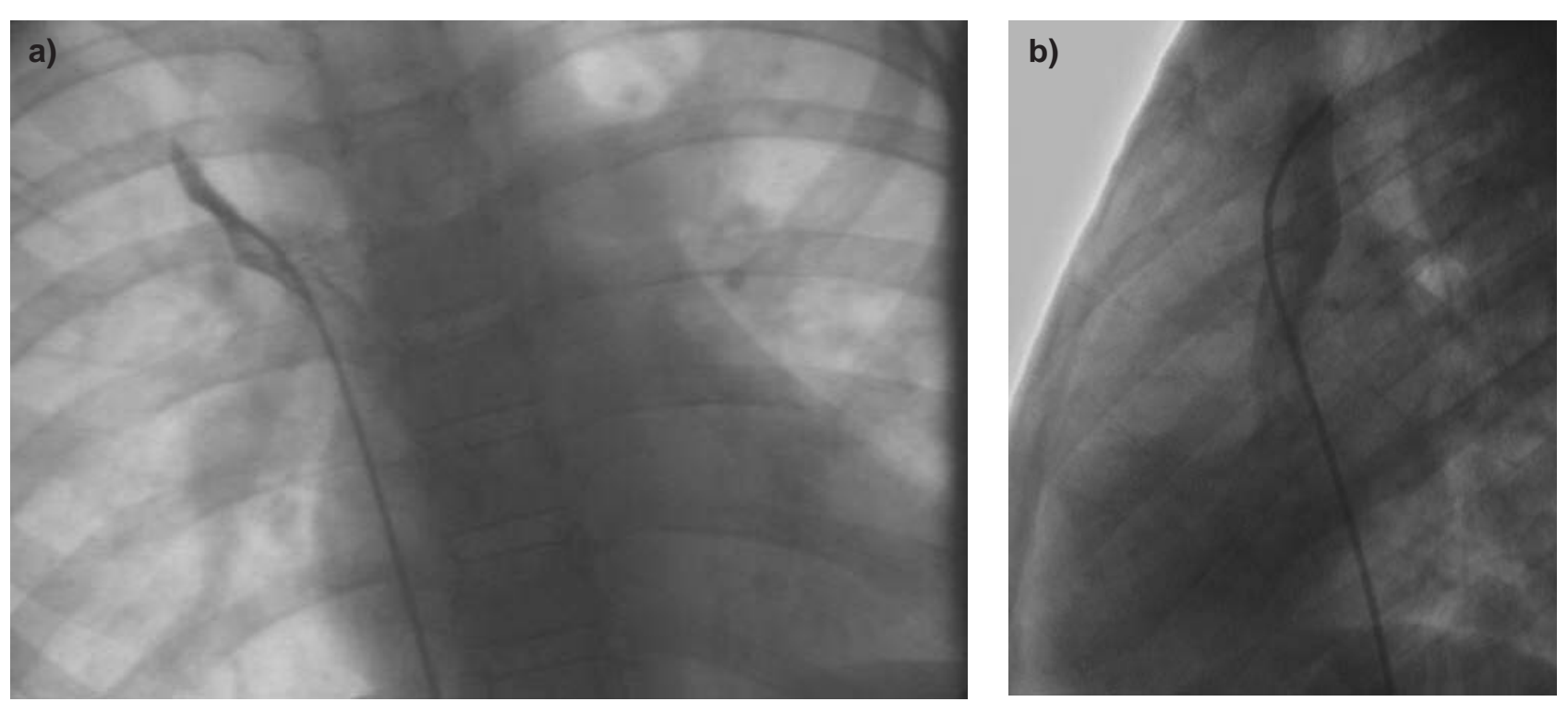

Figure 1. - Angiography shows drainage of anomalous pulmonary vein to SVC (Fig. 1a) and a dilated SVC (Fig. 1b).

patch with 5-0 polypropylene so that it could be drained into the left atrial cavity (Figure 2). The suture line of the intraatrial patch was placed away from the sinus node and the pulmonary veins. The SVC defect was repaired with a pericardial patch. The aortic clamp was released, and the patient was weaned off bypass. The sternotomy was closed, and patient's sinus rhythm was recovered.

The postoperative course was uncomplicated, and the patient was discharged on the seventh postoperative day. At discharge, an echocardiography investigation showed an LVEF of 55\% and mild TR with a PAP of $22 \mathrm{mmHg}$. She has been followed in a Cardiology Clinic every year ever since. She had an echocardiography revealing mild TR and mild RV dilatation with PAP of $43 \mathrm{mmHg} 9$ months ago. Currently at 4.5 years' follow-up, she is on no medications and remains asymptomatic.

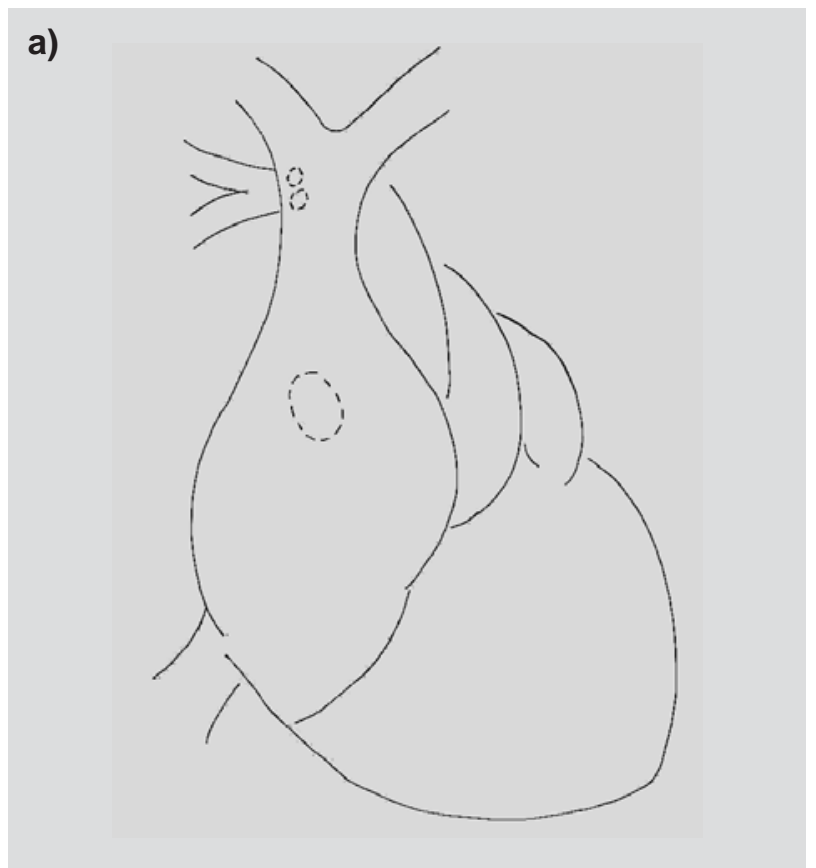

\section{Discussion}

Surgical repair for PAPVC to the SVC ideally includes a complete closure of the septal defect and redirection of the anomalous pulmonary veins into the left atrium without pulmonary venous or SVC obstruction or injury of the sinus node or its blood supply. However, when the veins enter further up the SVC, surgical treatment can be more complex [1]. Most commonly, surgical correction of these lesions is performed using the internal patch technique, or a modification thereof, to redirect the anomalous pulmonary venous return through the sinus venosus defect by baffling these structures with a pericardial or synthetic patch with or without performing a patch cavoplasty as needed $[3,4]$. If the insertion of the pulmonary veins is more than $2 \mathrm{~cm}$ above the atriocaval junction, the surgeon may face a challenging

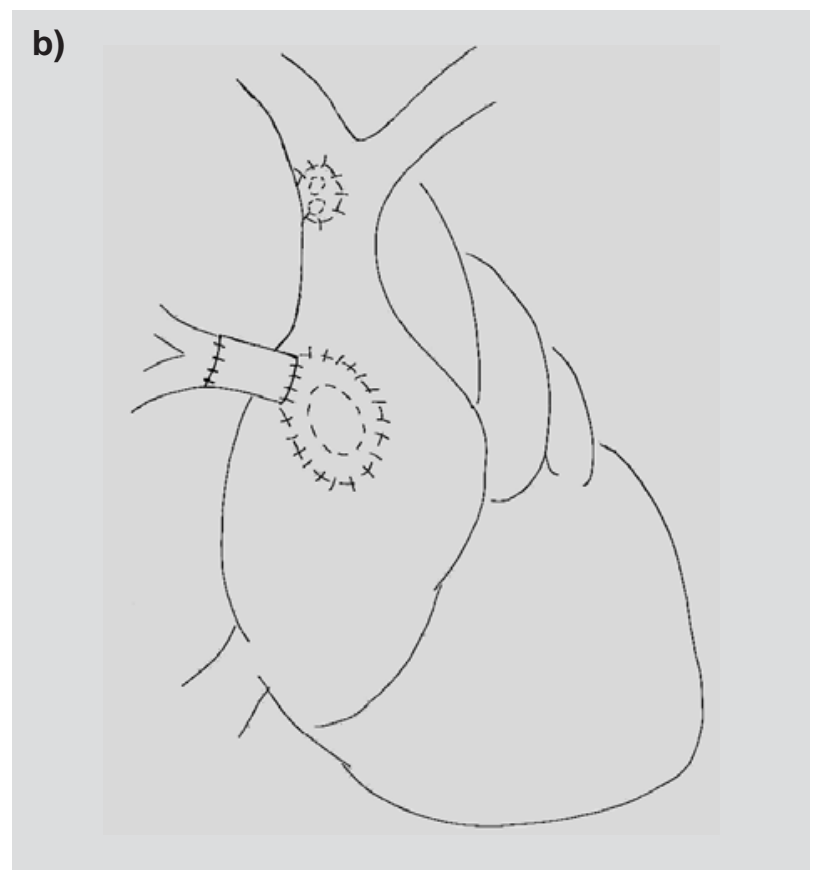

Figure 2. - Scheme of proposed transposition of the right anomalous pulmonary vein from the superior vena cava (Fig. 2 a) to the right atrium, creating a venous return into the left atrium by using the intra-atrial baffling (Fig. 2b). 
repair. Some of the techniques have been associated with significant morbidity including obstruction of the pulmonary vein orifices, SVC stenosis or obstruction, and atrial arrhythmias, including atrial flutter or atrial fibrillation (5-7).

In 1984, Warden and colleagues [8] reported a new technique for high PAPVC, in which caval continuity was established by direct cavoatrial anastomosis. The SVC was divided above the orifices of the anomalous pulmonary veins, and the cephalic end of the divided SVC was then anastomosed directly to the right atrial appendage after amputation of the tip. A patch within the right atrium diverted the pulmonary blood flow from the orifice of the SVC through the associated sinus venosus ASD. The caudal end of the divided SVC was closed by sutures. Further clinical experiences with this technique or a modified one have been reported by other authors $[1,3,9,10]$. De Leon and coworkers [11] have described an incision crossing the atriocaval junction. Having recognized that the incision was carried across the region of the sinoatrial node, they subsequently modified their approach by creating two separate incisions, one in the lateral atrial wall and one on the distal SVC, to avoid injury to the sinus node or its artery.

In our patient, we applied an innovation for the reconstruction of the high PAPVC. The connection of the right anomalous pulmonary veins was separated from the SVC. Then the proximal end of the extended pulmonary vein was anastomosed directly to the RA. In this technique, two autologous pericardial patches were needed to repair the pulmonary orifices on the SVC and the dilated ASD. The procedure had some advantages. Firstly, it avoided long baffles and extensive SVC patching. In contrast to the Warden procedure, the SVC was not divided into the cephalic and caudal ends; therefore, the caval continuity was intact. In the SVC translocation with the highest anomalous pulmonary vein, it can be assumed that the cephalic end of the divided SVC becomes more distant from the right atrial appendage and the cavoatrial anastomosis has more tension and likelihood of stenosis [1]. Another advantage of this technique was the avoidance of the creation of conduits inside the SVC. In our technique, however, the foreign material as a tube graft was settled to enhance the right pulmonary vein and redirect anomalous pulmonary venous flow into the LA.

The repair of the high insertion of the anomalous pulmonary veins by redirecting the venous return through the sinus venosus ASD by usging intraatrial baffling can be a good choice with a favorable longterm prognosis. The reanastomosis to the RA and extension of the right anomalous pulmonary vein is a safe and effective correction for PAPVC with high insertion into the SVC, and avoids long baffles, extensive SVC patching, and caval translocation.

\section{Riassunto}

Nel corso degli anni, varie tecniche sono state introdotte per la riparazione chirurgica della connesione anomala delle vene polmonari destre alla vena cava superiore. Qui riportiamo il caso di una ragazza di 9 anni, venuta alla nostra osservazione per dispnea e cianosi periferica. L'ecocardiogramma preoperatorio e l'angiografia confermavano la diagnosi di ritorno venoso polmonare anomalo parziale. Sotto bypass cardiopolmonare, il difetto interatriale è stato dilatato, e la vena polmonare anomala è stata anastomizzata all'atrio destro e ridiretta all'atrio sinistro attraverso un pacth intraatriale e un graft. Il decorso intra e postoperatorio è stato senza complicazioni, e la paziente è in buone condizioni cliniche a 4.5 anni di follow-up.

\section{References}

1. Nakahira A, Yagihara T, Kagisaki K, et al. Partial anomalous pulmonary venous connection to the superior vena cava. Ann Thorac Surg 2006; 82(3): 978-82.

2. Lewis FJ. High defects of the atrial septum. $J$ Thorac Cardiovasc Surg 1958; 36: 1-5.

3. Shahriari A, Rodefeld MD, Turrentine MW, Brown JW. Caval division technique for sinus venosus atrial septal defect with partial anomalous pulmonary venous connection. Ann Thorac Surg 2006; 81(1): 224-9.

4. Baron O, Roussel JC, Videcoq M, Guérin P, Gournay V, Lefevre M. Partial anomalous pulmonary venous connection: correction by intra-atrial baffle and cavo-atrial anastomosis. J Card Surg 2002; 17(2): 166-9.

5. Stewart S, Alexon C, Manning J. Early and late results of repair of partial anomalous pulmonary venous connection to the superior vena cava with a pericardial baffle. Ann Thorac Surg 1986; 41: 498-501.

6. Freiedli B, Guerin R, Davignon A, Fouron JC, Stanley P. Surgical treatment of partial anomalous pulmonary venous drainage: a long-term follow-up study. Circulation 1972; 45: 159-70.

7. Trusler GA, Kazenelson G, Freedom RM, Williams WG, Rowe RD. Late results following repair of partial anomalous pulmonary venous connection with sinus venosus atrial septal defect. J Thorac Cardiovasc Surg 1980; 79: 776-81.

8. Warden HE, Gustafson RA, Tarnay TJ, Neal WA. An alternative method for repair of partial anomalous pulmonary venous connection to the superior vena cava. Ann Thorac Surg 1984; 38: 601-5.

9. Gustafson RA, Warden HE, Murray GF. Partial anomalous pulmonary venous connection to the superior vena cava. Ann Thorac Surg 1995; 60(Suppl): 614-7.

10. Gaynor JW, Burch M, Dollery C, Sullivan ID, Deanfield JE, Elliott MJ. Repair of anomalous pulmonary venous connection to the superior vena cava. Ann Thorac Surg 1995; 59: 1471-5.

11. DeLeon SY, Freeman JE, Ilbawi MN, et al. Surgical techniques in partial anomalous pulmonary veins to the superior vena cava. Ann Thorac Surg 1993; 55: 1222-6. 